Running head: Leisure and Adjustment

\author{
Adolescent Leisure Dimensions, Psychosocial Adjustment, \\ and Gender Effects
}

\author{
Graham L. Bradley ${ }^{\mathrm{a}}$ and Brad C. Inglis ${ }^{\mathrm{b}}$ \\ Griffith University, Queensland
}

a Graham Bradley [Corresponding Author]

School of Psychology and Behavioural Bases of Health Research Centre,

Griffith University,

Queensland, 4222. Australia.

Phone: +617 5552 8743. Fax: +617 5552 8291. Email: g.bradley@griffith.edu.au

b Brad Inglis

School of Psychology and Behavioural Bases of Health Research Centre, Griffith University,

Queensland, 4222. Australia.

Phone: +617 5552 7151. Fax: +617 5552 8291. Email: b.inglis@ griffith.edu.au 
Adolescent Leisure Dimensions, Psychosocial Adjustment, and Gender Effects

\begin{abstract}
Leisure provides the context for much of adolescent behavior and development. While both theory and research point to the benefits of participation in leisure activities that are highly structured, the association between structured leisure and psychosocial adjustment is not uniformly high. This paper presents a model of adolescent leisure comprising three dimensions: structure, effort, and social contact. Adolescent adjustment is hypothesized to increase with participation in activities characterized by each of these attributes. Adjustment is also predicted to vary with gender, and with the interaction of gender and leisure participation. These propositions were tested in a questionnaire-based study of 433 Australian adolescents. Results revealed majority support for hypotheses pertaining to the positive effects of the leisure dimensions, and for gender differences in leisure participation and adjustment. Evidence was also obtained of gender-differentiated effects of leisure on adjustment, with social leisure predicting adjustment more strongly in females than males.
\end{abstract}

Keywords:

Adolescence; leisure; psychosocial adjustment; gender 


\section{Adolescent Leisure Dimensions, Psychosocial Adjustment, and Gender Effects}

Adolescents have approximately half their waking hours available for leisure (Larson \& Verma, 1999). During this time, they engage in varied activities that may include individual and team sports, hobbies and creative pursuits, shopping, socializing, use of social network sites, and hanging out with friends. Just like family and school, these leisure activities provide important contexts for adolescents to develop qualities such as self-worth, self-control, and social connectedness (Caldwell \& Smith, 2006; Eccles, Barber, Stone, \& Hunt, 2003; Hansen, Larson, \& Dworkin, 2003).

Despite considerable research demonstrating links between adolescent leisure and adjustment (Mahoney, Vandell, Simpkins, \& Zarrett, 2009), several issues remain unresolved. Substantive issues include: What types of leisure involvement contribute to adolescent psychosocial adjustment? Do the effects of leisure participation differ between genders? Crossing these issues are method-related questions: What is the most appropriate way to differentiate between leisure activities? How should leisure activities be selected for study? The current study addresses these questions.

\section{Differentiation of Leisure Activities in Past Research}

Leisure activities are activities that people do during their spare time, usually on a discretionary basis for intrinsic pleasure (cf. Mannell \& Kleiber, 1997). Much of the past research has divided leisure activities into structured and unstructured categories (Larson \& Verma, 1999; Osgood \& Anderson, 2004). Structured activities are those in which timing and duration of participation are prescribed, goals are predetermined, dress is standardized, and adherence to rules is monitored by adults. In contrast, unstructured leisure is more spontaneous, with direction and duration determined by the participants themselves (Abbott \& Barber, 2007). 
Research based on this distinction has found that participation in structured leisure is associated with high levels of school adjustment and psychological wellbeing, and low levels of internalizing symptoms, externalizing behaviors, and health risk behaviors (Eccles \& Barber, 1999; Eccles et al., 2003; Mahoney, Stattin, \& Lord, 2004; Mahoney et al., 2009; Osgood \& Anderson, 2004; Osgood, Anderson, \& Schaffer, 2005; Trainor, 2010). In some research (e.g., Denault \& Poulin, 2009; Fredricks \& Eccles, 2006, 2008; Mahoney et al., 2004), these effects have been demonstrated longitudinally and/or after controlling for factors that predict self-selection into activities. These differentiated effects on adjustment are consistent with theories of adolescent deviance. For example, social control theory (Hirschi, 1969) maintains that problem behaviours are most likely to occur when bonds between individuals and conventional societal institutions (e.g., family, school, church) are severed; unstructured leisure activities potentially weaken these bonds, whereas structured activities reinforce them. Routine activities theory (e.g., Osgood \& Anderson, 2004) similarly emphasises the contribution to deviant behaviour of time regularly spent with peers in unsupervised settings.

While research shows that positive adolescent outcomes more often accompany structured than unstructured leisure, several caveats apply. First, much of the research (e.g., Guest \& McRee, 2009; Kort-Butler \& Hagewen, 2011) has been limited to evaluations of school-based extracurricular activities. Findings from these studies may not generalize to broader leisure contexts. Second, many factors moderate the impact of structured leisure. For example, effects depend on the nature, breadth, and frequency of leisure involvement, and with the ethnicity and socioeconomic background of participants (Busseri, Rose-Krasnor, Willoughby, \& Chalmers, 2006; Fredricks \& Eccles, 2008). 
Third, effects vary between specific activities within the broad categories of structured and unstructured leisure. For example, while involvement in school-based clubs and community service activities provide uniformly positive outcomes, involvement in other structured activities such as competitive team sports and some arts activities are sometimes associated with less favourable outcomes (Eccles \& Barber, 1999; Fredricks \& Eccles, 2008; Kort-Butler \& Hagewen, 2011; Mahoney, et al., 2009). Researchers (Caldwell \& Smith, 2006; Shaw, Kleiber, \& Caldwell, 1995) have also observed considerable within-category differences in the correlates of unstructured activities. Abbott and Barber (2007), for example, found that dedicated hobbies and unstructured sports afforded many positive initiative- and identity-building experiences, whereas other unstructured activities, such as television-watching, provided few developmental benefits. In short, the categories of structured and unstructured leisure are neither entirely homogenous, nor entirely opposing in their effects.

As a result of the mixed findings regarding at least some structured and unstructured leisure, authors (Abbott \& Barber, 2007; Caldwell \& Smith, 2006) have argued that researchers must differentiate more precisely between leisure activities. To not do so risks falsely attributing psychosocial benefits of leisure activities to their structural qualities, rather than to other ways in which they differ. One approach evident in recent work (e.g., Guest \& McRee, 2009; Mahoney et al., 2009; Rutten et al., 2007) is to identify micro-contextual variables pertaining to the quality of the leisure experience that mediate the impact of structure on youth outcomes. Examples of such contextual variables include level of participant safety, autonomy and commitment, intensity of involvement, extent of participation in decision-making, ratio of successes to failures, sociomoral group atmosphere, and quality of peer and leader-participant relationships. While the value of this process-variable approach is yet to be fully realised, a potential shortcoming is that it may generate a very long list of moderating 
factors. As an alternative to both the structured versus unstructured leisure dichotomy and to the micro-process approach, we propose a three-dimensional framework in which to understand leisure involvement and explore its impact upon adolescent adjustment.

\section{A Three-Dimensional Framework for Understanding Leisure Activities}

In our view, leisure structure represents not a dichotomy, but a continuum ranging from highly pre-planned, rule-governed, and adult-controlled activities at one pole, to highly spontaneous, informal, and participant-directed activities, at the other. Moreover, leisure activities vary in ways other than the extent to which they are structured, with more precise predictions as to leisure impacts likely if activities are distinguished on additional grounds. One such additional criterion is the extent to which leisure involves social contact. Clearly, this is not a single or simple dimension of difference, with finer distinctions potentially made based on such attributes as the nature of the other person's presence (actual versus virtual), the relationship to the other person (e.g., friend versus family member), the extent of interaction taking place, the number and diversity of others present, and so on. Social interactions differ in many ways (e.g., warmth, conflict, supportiveness) that are relevant to adolescent psychosocial outcomes. Research (e.g., Fawcett, Garton, \& Dandy, 2008; Trainor et al., 2010) has demonstrated that participation in leisure activities involving at least minimal levels of social contact predicts such outcomes as participant self esteem, life satisfaction, and negative mood.

A further leisure dimension is the extent to which activities require the application of physical, cognitive, emotional, creative, and/or other types of effort and skills (Fawcett et al., 2008). Alternative terms include "achievement" leisure (Passmore \& French, 2000) versus "relaxed" (Eccles \& Barber, 1999) or "passive" leisure (Fawcett et al., 2008). This dimension ranges from leisure pursuits that are very demanding, challenging and difficult (e.g., elite athletics, chess competitions) to those that are “easy”, casual, and relaxing (e.g., sunbathing, browsing social media sites). 
With this background, the core propositions underlying the current research can be stated. First, leisure activities vary in more ways than just structure; The extent of social contact afforded, and the amount of effort demanded, are also critical attributes. While each of these dimensions has been recognized in different prior studies, we can locate no prior work that has adopted a framework involving all three. Second, the three dimensions are relatively independent of each other; All combinations are possible (although not equally common).

Third, all dimensions are positively and uniquely related to psychosocial wellbeing, with each contributing to some indices of adjustment more than others. The beneficial, albeit variable, effects of structure are well established and partly reviewed above. The impact of leisure involving social interaction is also generally favourable, with positive effects having been found on self-esteem, identity development, wellbeing, prosocial commitments, and life satisfaction (e.g., Eccles \& Barber, 1999; Trainor et al., 2009). Other evidence, however, shows that time spent with peers may be related to behavioural problems including delinquency, substance use, and sexual activity (e.g., Barnes et al., 2007; Sharp et al., 2007). Finally, there is limited, but quite consistent, evidence of links between effortful leisure and adolescent adjustment (Caldwell \& Smith, 2006; Mahoney et al., 2004). For example, Passmore and French (2000) found that participation in achievement leisure predicted self-efficacy, competence, and self-worth, which, in turn, were associated with better mental health.

\section{Selecting Adolescent Leisure Activities for Study}

Researchers have used a range of approaches in the study of adolescent leisure. Key issues include (a) whether one or multiple activities are studied, (b) whether participation is assessed in terms of breadth, intensity, duration, and/or history of involvement, (c) whether the activity/ies are defined in terms of relatively broad and abstract categories (e.g., structured activities, creative activities) or in terms of more 
narrow and concrete entities (e.g., hockey, video-gaming), (d) whether the activity/ies are chosen by the researcher or by the research participants, and (e), if the latter, whether selection is based on time spent in the activity, personal expressiveness or meaningfulness, enjoyment, or another criterion.

The approach adopted in the current study was to require participants to nominate up to four activities that occupy most of their spare time, and then report the degree to which their own participation in these activities involves (a) the presence of others, (b) effort, and (c) structure in the form of rules, time-limits, uniforms, and so on. Participants also recorded the number of hours per week in which they engage in each activity. With this information, we computed a temporally-weighted measure of the degree to which participants' leisure lifestyle was social, effortful, and structured.

\section{Gender Differences in Wellbeing, Leisure, and their Interaction}

Gender differences in indices of psychosocial adjustment are well documented (Galambos, Berenbaum, \& McHale 2009). Compared to males, adolescent females generally report higher levels of internalized disorders including anxiety and depression, lower levels of self-esteem, and fewer conduct problems (Fredricks \& Eccles, 2008; Perry \& Pauletti, 2011; Shaw et al., 1995). In contrast, no gender differences are generally found on other adjustment variables like social connectedness and relationships with parents (Lee et al., 2001; Williams \& Galliher, 2005). In the current study, we tested and expected to replicate these findings.

Gender differences are also evident in many aspects of leisure activity participation (see Barnes et al., 2007; Bohnert, Kane, \& Garber, 2008; Kort-Butler \& Hagewen, 2011; Trainor et al., 2010; Veal, 2005). Research shows that both male and female adolescents spend much of their leisure time either in group activities and/or in sedentary pursuits (e.g., listening to music, watching television, browsing the internet, or just relaxing). Beyond this, however, males spend more time alone, and more time 
playing video and computer games and participating in sporting and outdoor physical activities, while females spend more time talking to friends, shopping, reading, and engaging in creative activities such as music, dance, and art (Barnes et al., 2007; Sharp et al., 2007; Shaw et al., 1995; Trainor et al. 2010, Veal, 2005). Consistent with past research, we expected a higher proportion of females' than males' leisure time to involve social contact. Insufficient evidence exists to hypothesize gender differences in time spent in structured activities and in effortful leisure activities.

While gender differences in psychosocial adjustment and leisure activities are well established, the evidence is more limited and equivocal regarding the role of gender in moderating the relationships between leisure participation and adjustment. Most studies (e.g., Bohnert et al., 2008; Kort-Butler \& Hagewen, 2011; Mahoney et al., 2004) have found no or few gender moderating effects. Other research (e.g., Barnes et al., 2007; Fredricks \& Eccles, 2006, 2008; Shaw et al., 1995; Tracy \& Erkut, 2002) has, however, yielded contrary evidence. For example, Mahoney and Stattin (2000) found that involvement in unstructured leisure activities was especially problematic for males' antisocial behavior. Fredricks and Eccles (2006) reported that participation in school clubs was related to alcohol and substance use in boys only, whilst these researchers' 2008 study found that school clubs activity predicted a reduced decline over time in school value among males but not among females. Taken together, this evidence suggests that the impact of leisure structure may be stronger among male than among female adolescents. In addition, there is evidence that participation in leisure activities that entail social interaction has a greater impact on males' than on females' psychosocial adjustment. For example, Barnes et al. (2007) reported that the negative effects of "peer time" on risky sexual behaviors were stronger for males than females. Hypotheses

We tested four hypotheses: 
1. Each of the leisure dimensions of (a) social contact, (b) effort, and (c) structure is positively correlated with psychosocial adjustment.

2. Female adolescents report greater participation in leisure activities that involve social contact than do males.

3. Males report higher levels of (a) self-esteem and (b) conduct problems than do females, while (c) females report higher levels of emotional symptoms than do males. (No gender differences in family relations or social connectedness were predicted).

4. The relationships between leisure participation and psychosocial adjustment are moderated by gender, with the effects of (a) structure and (b) social contact stronger for males than for females.

Hypotheses 2 and 4 were tested in two ways: once using continuous measures of the leisure dimensions, and once comparing levels of adjustment in groups of adolescents formed using median splits on the three leisure dimensions.

\section{Method}

\section{Participants}

Participants were recruited from a single public secondary school located in a middle class suburb in Queensland, Australia. All students in grades 8-11 in attendance on the days of testing were invited to participate. The sample comprised 433 adolescents (mean age $=14.51$ years, $\mathrm{SD}=1.70)$, including 193 males $(44.6 \%)$ and 209 females (48.3\%) (31 gender unknown). Most (89\%) were born in Australia or New Zealand, and most (95\%) nominated English as their first language.

\section{Measures}

Leisure Time Use. After reading instructions that distinguished "work time" and "spare time", participants were asked to indicate the four activities that they spend the largest 
proportion of their spare time doing, and to indicate the number of hours in the average week they engage in each activity. They then described the way in which they typically participate in each activity by responding to three questions, one relating to the degree of social contact they experience when engaged in the activity (i.e., "to what extent do you do this activity alone versus in the presence of others?"), one relating to the degree of effort required (i.e., "to what extent does this activity require you to use effort and/or skills?"), and one relating to the degree of structure involved (i.e., "to what extent does this activity have rules, time-limits, uniforms, or other things like that when you do it?”). Responses were on 5-point Likert-type scales that varied by leisure dimension, with the extreme poles represented by I always do it alone versus I always do it with others (social ), this activity requires no effort and/or skill when I do it versus this activity requires heaps of effort and/or skill when I do it (effort), and this activity has no rules, time-limits, uniforms, etc when I do it versus this activity has heaps of rules, timelimits, uniforms, etc when I do it (structure).

Rosenberg Self Esteem Scale (Rosenberg, 1965). The Rosenberg Self-Esteem scale was used to measure global self-esteem. Total scores on this 10-item scale range from 10-40, with higher scores representing higher self esteem. Internal consistency is .80 or higher in youth samples (e.g., Bradley, 2010; Williams \& Galliher, 2006).

Strengths and Difficulties - Youth Self Report (SDQ-YSR; Goodman, 2001). The emotional symptoms and conduct problems subscales of the SDQ-YSR were used to measure internalising and externalising symptoms, respectively. These subscales have moderate-high reliability, sound validity, and established capacity to discriminate between low and high risk groups (Goodman, Meltzer, \& Bailey, 1998).

Relationship with Parents. A three-item scale based on Aseltine (1995) and used by Bradley (2010) assessed perceived quality of relationships with parents. Responses on a 5-point scale were averaged such that high scores represent close 
relationships with parents. Bradley reported a Cronbach's alpha of .86 for this scale, and evidence of concurrent validity.

Social Connectedness Scale - Revised (SCS-R; Lee, Draper \& Lee, 2001). To complement the measures of individual and family adjustment, the SCS-R was used to measure the degree of interpersonal closeness experienced between an individual and his or her social world. A sample item is "I feel understood by the people I know." One of the 20 items was erroneously omitted. High scores represent high social connectedness. Williams and Galliher (2006) provide evidence of scale reliability and validity.

Procedure

After receipt of necessary ethical clearances and school approvals, the students read and retained an information sheet, gave their written, informed consent, and completed the questionnaire under teacher supervision in a "pastoral care" class. In accord with the University ethics committee determination, a passive parental consent procedure was adopted.

\section{Results}

Participants reported engaging in a wide range of leisure activities, $34.1 \%$ of which could be categorized as television/video/computer-related, 18.8\% as informal socializing, $10.8 \%$ as team sports, $9.6 \%$ as individual sports, $5.2 \%$ as shopping, and $5.1 \%$ as dancing/singing/acting. Six participants did not report hours spent in any activity and were excluded from analyses involving the leisure dimensions. Following past practice (e.g., Osgood \& Anderson, 2004), the number of hours per activity was capped at 50, and the 33 participants who reported total leisure hours in excess of 100 , after applying this capping, were excluded from analyses involving the leisure data. Final N = 394 for analyses involving the leisure dimensions. 
To assess the extent of involvement in social, effortful, and structured leisure activity, scores for each dimension were computed using a three-step procedure. First, the total number of leisure hours reported across all activities was calculated for each participant. Second, for each leisure activity nominated, the proportion of the total leisure hours spent was multiplied by the response to the question pertaining to each leisure dimension. Third, the mean value for each dimension was calculated by averaging these weighted scores across the four (or fewer) activities.

Table 1 presents descriptive data. On average, respondents indicated their leisure activity to involve high levels of social contact, some degree of effort, and lesser amounts of structure.

[Insert Table 1 about here]

Correlates of Leisure Activity Participation and Psychosocial Adjustment

Table 2 presents zero-order correlations. In accord with hypothesis 1, the majority of the correlations ( 9 of 15) between measures of leisure activity and psychosocial adjustment were significant. The major exception was in relation to conduct problems, which was uncorrelated with all three leisure dimensions.

[Insert Table 2 about here]

Gender Differences in Leisure Participation and Psychosocial Adjustment

Hypothesis 2 was examined using an independent-groups $t$-test comparing the extent of social contact in the leisure activities of males and females. As expected, females reported more leisure activities involving social contact, $t(359)=-3.19, p<.01$, partial $\eta^{2}=.03$. Significant effects were also found for effortful leisure participation, $t(359)=5.12, p<.001, \eta_{\mathrm{p}}{ }^{2}=.07$, and structured leisure participation, $t(359)=2.34, p<$ $.05, \eta_{\mathrm{p}}{ }^{2}=.02$, with males reporting greater participation in both leisure types. Details are given in Table 1. 
Activity categories were formed using median splits on each leisure dimension, with participants assigned to one of the eight resulting leisure categories. Chi-square analysis revealed a significant association between gender and leisure group membership, $\chi^{2}(\mathrm{~N}=393, d f=7)=33.79, p<.001$, Cramer's $V=.29$. The adjusted residuals indicated a disproportionately high number of females in the high social, low effort, low structure group (Adjusted Residual $[A R]=3.9$ ), and a disproportionately high number of males in the low social, high effort, high structure group (AR = 3.6).

To test hypothesis 3, a one-way MANOVA was conducted with gender as the single independent variable (IV) and the five measures of psychosocial adjustment as the dependent variables (DVs). The multivariate effect was significant, $F(5,336)=$ $19.48, p<.001, \eta_{\mathrm{p}}{ }^{2}=.23$. Univariate main effects were examined for all DVs with a Bonferonni correction applied $(\alpha=.01)$. As shown in Table 1 , univariate effects were found for internalising symptoms, $F(1,340)=36.30, p<.001, \eta_{\mathrm{p}}{ }^{2}=.10$, and self esteem, $F(1,340)=9.02, p=.003, \eta_{\mathrm{p}}{ }^{2}=.03$, with males having higher levels of self esteem and lower levels of internalising symptoms. The effect on social connectedness was marginally significant $\left(p=.01, \eta_{\mathrm{p}}^{2}=.02\right.$ ). These results support hypothesis 3(a) (self-esteem) and 3(c) (emotional symptoms) but not 3(b) (conduct problems). The Moderating Effect of Gender on the Leisure Participation - Adjustment

\section{Relationship}

Hypothesis 4 predicted that the effects of leisure participation on psychosocial adjustment would vary by gender. Five moderated hierarchical multiple regression analyses, one per adjustment index, were performed. In each analysis, gender was entered at step 1, the three leisure dimensions (all in deviation form) at step 2, and terms representing the interactions between gender and the three leisure dimensions at step 3. Age was also entered as a control at step 1. Results are summarized in Table 3. 
The total variance explained ranged from $4.5 \%$ (conduct difficulties) to $18.2 \%$ (social connectedness). Gender was a significant predictor of all adjustment criteria except relationship with parents, while age was not significant in any analysis. After controlling for these demographic variables, social leisure predicted all adjustment indices except conduct difficulties. Effortful leisure predicted self-esteem only, and structured leisure did not predict any of the criteria. Addition of the block of three Gender $x$ Leisure interaction terms did not contribute significantly in any of the analyses. However, one of these terms, Gender x Social activity, predicted each of conduct difficulties, relationships with parents, and social connectedness. Simple slopes analyses, controlling for all other predictors, showed that, as the proportion of leisure time spent in social activities increased, (a) males' but not females' conduct difficulties increased, (b) females' but not males' relationships with their parents improved, and (c) levels of social connectedness increased more rapidly in females than males.

The differential effects of leisure activities for males and females were further examined by way of a 2 (gender) x 8 (leisure category) MANOVA, with the five adjustment indices as DVs. Significant multivariate main effects was found for gender, $F(5,319)=15.92, p<.001, \eta_{\mathrm{p}}^{2}=.20$, and for leisure category, $F(35,1615)=2.54, p<$ $.001, \eta_{\mathrm{p}}{ }^{2}=.05$. The Gender $\mathrm{x}$ Leisure interaction was also significant, $F(35,1615)=$ $1.62, p=.012, \eta_{\mathrm{p}}{ }^{2}=.03$. Univariate effects were examined using an alpha level of.01. Gender differences were as reported in Table 1 and are not discussed further. Significant univariate effects for leisure category were found for internalising symptoms, $F(7,323)=3.63, p=.001, \eta_{\mathrm{p}}{ }^{2}=.07$, and social connectedness, $F(7,323)=$ $6.36, p<.001, \eta_{\mathrm{p}}{ }^{2}=.12$. The interaction was significant only for social connectedness, $F(7,323)=4.34, p=.001, \eta_{\mathrm{p}}{ }^{2}=.09$. Comparison of the levels of social connectedness in group 1 (high on all three dimensions) and group 8 (low on all dimensions) revealed a significant difference, $t(133)=5.53, p<.001, \eta_{\mathrm{p}}{ }^{2}=.19$, with group 1 reporting higher 
levels $(\mathrm{M}=4.64,99 \% \mathrm{CI}: 4.39-4.90)$ than group $8(\mathrm{M}=3.98,95 \% \mathrm{CI}: 3.76-4.20)$. The two leisure activity groups did not differ on the other four DVs. Hypothesis 4 was not supported.

Mean levels of social connectedness for groups defined by gender and social leisure group are plotted in Figure 2. As shown, among females, group 8 reported lower social connectedness than did the other seven groups, whereas this pattern was less evident for males. Independent-groups t-tests were performed on a post hoc basis separately for males and females to compare levels of social connectedness in members of group 8 versus all other groups combined. This comparison was significant for females, $t(195)=8.21, p<.001, \eta_{\mathrm{p}}{ }^{2}=.26$, but not for males, $t(168)=1.17, p=.243, \eta_{\mathrm{p}}{ }^{2}$ $=.01$. Plots similar to Figure 2 for the other four DVs showed greater between-group differentiation (that is, steeper "slopes") for females, than for males, with females in group 8 having average scores that departed from the sample mean in the unfavourable direction for these other four indices of adjustment. T-tests revealed that group 8 females differed from females in the remainder of the sample on self esteem, $t(196)=-$

$2.88, p<.01, \eta_{\mathrm{p}}{ }^{2}=.04$, internalising symptoms, $t(198)=3.15, p<.01, \eta_{\mathrm{p}}{ }^{2}=.05$, and relationship with parents, $t(188)=-2.97, p<.01, \eta_{\mathrm{p}}{ }^{2}=.04$.

[Insert Figure 2 about here]

\section{Discussion}

This study sought to enhance understandings of the relationships between adolescent leisure, gender, and psychosocial adjustment.

\section{Psychosocial Adjustment Correlates of Leisure Activity}

As expected, participants indicated that a large proportion of their waking hours are spent engaged in a diverse range of leisure activities. These included high levels of involvement in social leisure activities, somewhat less involvement in activities that required the application of skills and effort, and more modest involvement in structured 
leisure activities. Majority support was obtained for the prediction (H1) of positive relationships between involvement in these three dimensions of leisure and adjustment.

After controlling for other forms of leisure participation, psychosocial benefits were not associated with participation in structured leisure activities. This is contrary to the conclusions drawn in studies (e.g., Eccles et al., 2003; Trainor et al., 2010) that did not partial out the effects of other leisure dimensions. Several interpretations may be placed on the current finding. First, it suggests that past findings of positive effects associated with organized activities may have misattributed benefits to the structure inherent in these activities, while under-stating the roles played by the activities' socializing and effort components. Thus, the positive effects may be largely spurious, that is, due to the correlation of leisure structure with other beneficial leisure attributes. A second possibility is that the benefits are real, but the relative advantages of structured over unstructured leisure are limited to particular sub-types of activities. Past findings (e.g., Abbott \& Barber, 2007) of the differential effects of activities within both structured and unstructured groups provide support for this notion. Both these interpretations serve to underscore the value of differentiating between leisure activities along more than one dimension. A third possibility is that leisure structure was not measured appropriately in the current study. For example, we made no reference in our scale item to "adult supervision", and the characteristics we did attribute to structured activities (e.g., rules, time limits) may have unjustifiably implied a loss of autonomy. A different operationalisation may have provided greater support for the expected effect.

After controlling for gender and age, the leisure dimensions explained between $1 \%$ (conduct problems) and 13\% (social connectedness) of the variance in psychosocial adjustment. On the one hand, the failure to account for a high proportion of variance in these indices is not surprising, given their likely multi-determination. On the other hand, the weak link with adolescent conduct problems is contrary to much past research (e.g., 
Osgood \& Anderson, 2004). This supports the claim that the impact of leisure on these problems is not universal, but rather depends on micro-processes within specific contexts (Eccles \& Barber, 1999; Guest \& McRee, 2009; Rutten et al., 2007).

Gender Differences in Leisure Participation and Psychosocial Adjustment

Compared to their male counterparts, females were predicted and found to spend more of their leisure time in the presence of others. Support was also found for the hypotheses that males would have higher levels of self esteem, while females would display higher levels of internalising symptoms. With an adjustment to the alpha level in place, the prediction that males would report higher levels of conduct problems was not supported. Perhaps this null finding is indicative of an emerging generational effect, with other evidence suggesting that the gender gap in conduct problems has narrowed in recent years (Steffensmeier, Schwartz, Zhong, \& Ackerman, 2005).

\section{Gender Differences in the Adjustment Correlates of Leisure Participation}

We expected leisure structure and leisure social contact to have stronger effects on adjustment for males than for females. However, regression analyses revealed that only the interaction between gender and social leisure predicted adjustment, and the direction of this moderating effect did not accord with expectations. Specifically, participation in social activities was associated with increased conduct difficulties in males but not in females, and with stronger, positive effects on relationships with parents and social connectedness in females than in males. All three of these interaction effects thus suggest that social leisure is of greater benefit to females than to males. Perhaps these gender differences in the adjustment correlates of social leisure arise because the presence of other people during leisure time is more important for the normative psychosocial development of females than of males (Galambos et al., 2009). A second possibility is that the gender differences arise from a difference in the types of people with whom males and females interact, with male social leisure more often 
involving contact with antisocial peers. Third, the effect may be due to differences in the kinds of social activities preferred by males and females. Specifically, activities engaged in by males when in the presence of others are more likely to involve competition, risk-taking and rule-breaking, whereas social activities preferred by females more likely involve cooperative and creative pursuits (Perry \& Pauletti, 2011; Sharp et al., 2007; Trainor et al., 2009).

When participants were grouped into eight categories based on all three leisure dimensions, fewer between-group differences were observed among males than among females. These group effects were strongest on females' social connectedness. Thus, in females but not males, those who had below median levels of engagement in all leisure dimensions (group 8) reported lower levels of social connectedness than did those reporting above median levels on all dimensions. Post-hoc testing revealed that group 8 females also reported lower levels of self esteem and parent relationship quality, and higher levels of emotional symptoms, than did the remaining female members of the sample. While it is tempting to conclude that these adolescent females represent an atrisk group for poor psychological outcomes, the design of the current study does not permit causal conclusions: perhaps low levels of leisure participation promote poor psychological outcomes, perhaps prior maladjustment promotes low leisure participation, and perhaps reciprocal effects operate. To the extent that there is truth in the first of these interpretations however, interventions may usefully target the barriers to leisure participation experienced by this group of troubled young females.

\section{Limitations, Future Research and Implications}

The primary limitation of this study relates to the use of a cross-sectional and non-experimental design when evidence of causality is really needed. Research (e.g., Bohnert et al., 2008; Busseri et al., 2006) has provided longitudinal evidence that leisure and adjustment can reciprocally predict each other, yet similar evidence could not be 
obtained from the current design. Nonetheless, in line with the dose-response (or "biological gradient") argument used to strengthen inferences of causality in epidemiological research (Hill, 1965), our use of leisure scores that were weighted for relative duration of participation provided evidence consistent with a causal effect on adjustment.

Researchers should continue to investigate the impacts of leisure dimensions other than structure. To obtain more reliable and content valid measures, each dimension could be measured by multiple questions. The current measure of social leisure, for example, could be expanded to include items pertaining to many different dimensions of social contact, interaction and influence. A critical issue is whether three leisure dimensions represent the optimum compromise between parsimony and sensitivity. Future research could, for example, test a model in which each of the current dimensions is split into two, with the resulting six-dimensional model assessing the extent to which leisure involves (a) adult supervision, (b) predetermined processes and outcomes, (c) interaction with other people who are present, (d) communication with other people who are distant, (e) application of physical effort and skills, and (f) application of other (cognitive, creative) effort and skills. Data collection could also be extended to include other aspects of adolescents' lives, such as their family environment, patterns of paid work, and study commitments, all of which may moderate leisure-related effects.

Practically, just as past research (e.g., Eccles et al., 2003), has recommended the expansion of structured activity-based programs, the current findings suggest the importance of opportunities for adolescents to interact socially and in ways that encourage active, effortful engagement. Interventions need not be highly structured: Simply providing spaces in which adolescents can feel comfortable to interact may be sufficient. Such opportunities may be particularly important for enhancing the 
psychological wellbeing of the at-risk group of female adolescents who currently spend much of their leisure time in unstructured, low effort, solitary activities. 


\section{References}

Abbott, B. D., \& Barber, B. L. (2007). Not just idle time: Adolescents' developmental experiences provided by structured and unstructured leisure activities. The Australian Educational and Developmental Psychologist, 24, 59-81.

Aseltine, R. H. (1995). A reconsideration of parental and peer influences on adolescent deviance. Journal of Health and Social Behaviour, 36, 103-121.

Barnes, G., Hoffman, J. H., Welte, J. W., Farrell, M. P., \& Dintcheff, B. A. (2007). Adolescents' time use: Effects on substance use, delinquency and sexual activity. Journal of Youth and Adolescence, 36, 697-710.

Bohnert, A. M., Kane, P., \& Garber, J. (2008). Organized activity participation and internalizing and externalizing symptoms: Reciprocal relations during adolescence. Journal of Youth and Adolescence, 37, 239-250

Bradley, G. L. (2010). Skate parks as a context for adolescent development, Journal of Adolescent Research, 25, 288-323.

Busseri, M. A., Rose-Krasnor, L., Willoughby, T., \& Chalmers, H. (2006). A longitudinal examination of breadth and intensity of youth activity involvement and successful development. Developmental Psychology, 42, 1313-1326.

Caldwell, L. L, \& Smith, E. (2006). Leisure as a context for youth development and delinquency prevention. The Australian and New Zealand Journal of Criminology, 39, 398-418.

Deci, E. L., \& Ryan, R. M. (2000). The "what" and "why" of goal pursuits: Human needs and the self-determination of behavior. Psychological Inquiry, 11, 227-268.

Denault, A., \& Poulin, F. (2009). Intensity and breadth of participation in organized activities during the adolescent years: Multiple associations with youth outcomes. Journal of Youth and Adolescence, 38, 199-1213. 
Eccles, J. S., \& Barber, B. L. (1999). Student council, volunteering, basketball, or marching band: What kind of extracurricular involvement matters? Journal of Adolescent Research, 14, 10-43.

Eccles, J. S., Barber, B. L., Stone, M., \& Hunt, J. (2003). Extracurricular activities and adolescent development. The Journal of Social Issues, 59, 865-889.

Fawcett, L., Garton, A. F., \& Dandy, J. (2008). Influences of parents and peers in adolescent leisure activities. Australian Education and Developmental Psychologist, 25, 32-47.

Fredricks, J. A., \& Eccles, J. S. (2006). Is extracurricular participation associated with beneficial outcomes? Concurrent and longitudinal relations. Developmental Psychology, 42, 698-713.

Fredricks, J. A., \& Eccles, J. S. (2008). Participation in extracurricular activities in the middle school years: Are there developmental benefits for African American and European American youth? Journal of Youth and Adolescence, 37, 10291043.

Galambos, N. L., Berenbaum, S., \& McHale, S. (2009). Gender and gender role development in adolescence. In R. M. Lerner \& L. Steinberg (Eds.), Handbook of adolescent psychology (3rd ed., Vol. 1, pp. 305-357). New York: Wiley.

Goodman, R. (2001) Psychometric properties of the Strengths and Difficulties Questionnaire. Journal of the American Academy of Child and Adolescent Psychiatry, 40, 1337-1345.

Goodman, R., Melzer, H., \& Bailey, V. (1998). The strengths and difficulties questionnaire: A pilot study on the validity of the self-report version. European Child and Adolescent Psychiatry, 7, 125-130. 
Guest, A. M., \& McRee, N. (2009). A school-level analysis of adolescent extracurricular activity, delinquency, and depression: The importance of situational context. Journal of Youth and Adolescence, 38, 51-62.

Hansen, D. M., Larson, R. W., \& Dworkin, J. B. (2003). What adolescents learn in organized youth activities: A survey of self-reported developmental experiences. Journal of Research on Adolescence, 13, 25-55.

Hill, A. B. (1965). The environment and disease: Association or causation? Proceedings of the Royal Society of Medicine, 58, 295-300.

Hirschi, T. (1969). Causes of delinquency. Berkeley: University of California Press

Kort-Butler, L. A., \& Hagewan, K. J. (2011). School-based extracurricular activity involvement and adolescent self-esteem: A growth curve analysis. Journal of Youth and Adolescence. 40, 568-581.

Larson, R., \& Verma, S. (1999). How children and adolescents spend time across the world: Work, play and developmental opportunities. Psychological Bulletin, $125,701-736$.

Lee, R. M., Draper, M., \& Lee, S. (2001). Social connectedness, dysfunctional interpersonal behaviors, and psychological distress: Testing a mediator model. Journal of Counselling Psychology, 48, 310-318.

Mahoney, J. L., \& Stattin, H. (2000). Leisure activities and adolescent antisocial behavior: The role of structure and social context. Journal of Adolescence, 23, 113-127.

Mahoney, J. L., Stattin, H., \& Lord, H. (2004). Unstructured youth recreation centre participation and antisocial behavior development: Selection influences and the moderating role of antisocial peers. International Journal of Behavioral Development, 28, 553-560. 
Mahoney, J., Vandell, D., Simpkins, S., \& Zarrett, N. (2009). Adolescent out-of-school activities. In R. M. Lerner \& L. Steinberg (Eds.), Handbook of adolescent psychology (3rd ed., Vol. 2, pp. 228-269). New York: Wiley.

Mannell, R. C., \& Kleiber, D. A. (1997). A social psychology of leisure. Sate College, PA: Venture Publishing.

Osgood, D. W., \& Anderson, A. L. (2004). Unstructured socializing and rates of delinquency. Criminology, 42, 519-549.

Osgood, D. W., Anderson, A. L., \& Shaffer, J. N. (2005). Unstructured leisure in the after- school hours. In J.L. Mahoney, Larson, R.W. \& Eccles, J.S. (Eds.), Organised activities as contexts of development: Extracurricular activities, after-school and community programs. Mahwah, New Jersey: Lawrence Erlbaum Associates, Publishers.

Passmore, A., \& French, D. (2000). A model of leisure and mental health in Australian adolescents. Behaviour Change, 17, 208-220.

Perry, D. G., \& Pauletti, R. (2011). Gender and adolescent development. Journal of Research on Adolescence, 21, 61-74.

Randall, E. T., \& Bohnert, A. M. (2009). Organized activity involvement, depressive symptoms, and social adjustment in adolescence: Ethnicity and socioeconomic status as moderators Journal of Youth and Adolescence, 38, 1187-1198.

Rosenberg, M. A. (1965). Society and the adolescent self image. New Jersey: Princeton University Press.

Rutten, E. A., Stams, G. J. J. M., Biesta, G. J. J., Schuengel, C., Dirks, E., \& Hoeksma, J. B. (2007). The contribution of organized youth sport to antisocial and prosocial behavior in adolescent athletes. Journal of Youth and Adolescence, 36, 255-264.

Sharp, E. H., Coatsworth, J. D., Darling, N., Cumsille, P., \& Ranieri, S. (2007). 
Gender differences in the self-defining activities and identity experiences of adolescents and emerging adults. Journal of Adolescence, 30, 251-269.

Shaw, S. M., Kleiber, D. A., \& Caldwell, L. L. (1995). Leisure and identity formation in male and female adolescents: A preliminary examination. Journal of Leisure Research, 27, 245-263.

Steffensmeier, D., Schwartz, J., Zhong, S. H., \& Ackerman, J. (2005). An assessment of recent trends in girls' violence using diverse longitudinal sources: Is the gender gap closing? Criminology, 43, 355-406.

Trainor, S., Delfabbro, P., Anderson, S., \& Winefield, A. (2010). Leisure activities and adolescent psychological wellbeing. Journal of Adolescence, 33, 173-186.

Tracy, A. J., \& Erkut, S. (2002). Gender and race patterns in the pathways from sports participation to self-esteem. Sociological Perspectives, 45, 445-466.

Veal, A. J. (2005). Australia. In G. Cushman, A.J. Veal, \& J. Zuzanek (Eds.) Free time and leisure participation: International perspectives (pp. 17-40). Wallingford: Oxon.

Williams, K. L, \& Galliher, R. V. (2006). Predicting depression and self-esteem from social-connectedness, support, and competence. Journal of Social and Clinical Psychology, 25, 855-874. 
Table 1.

Descriptive Statistics for Leisure Dimensions and Adjustment Variables for the Full Sample and by Gender.

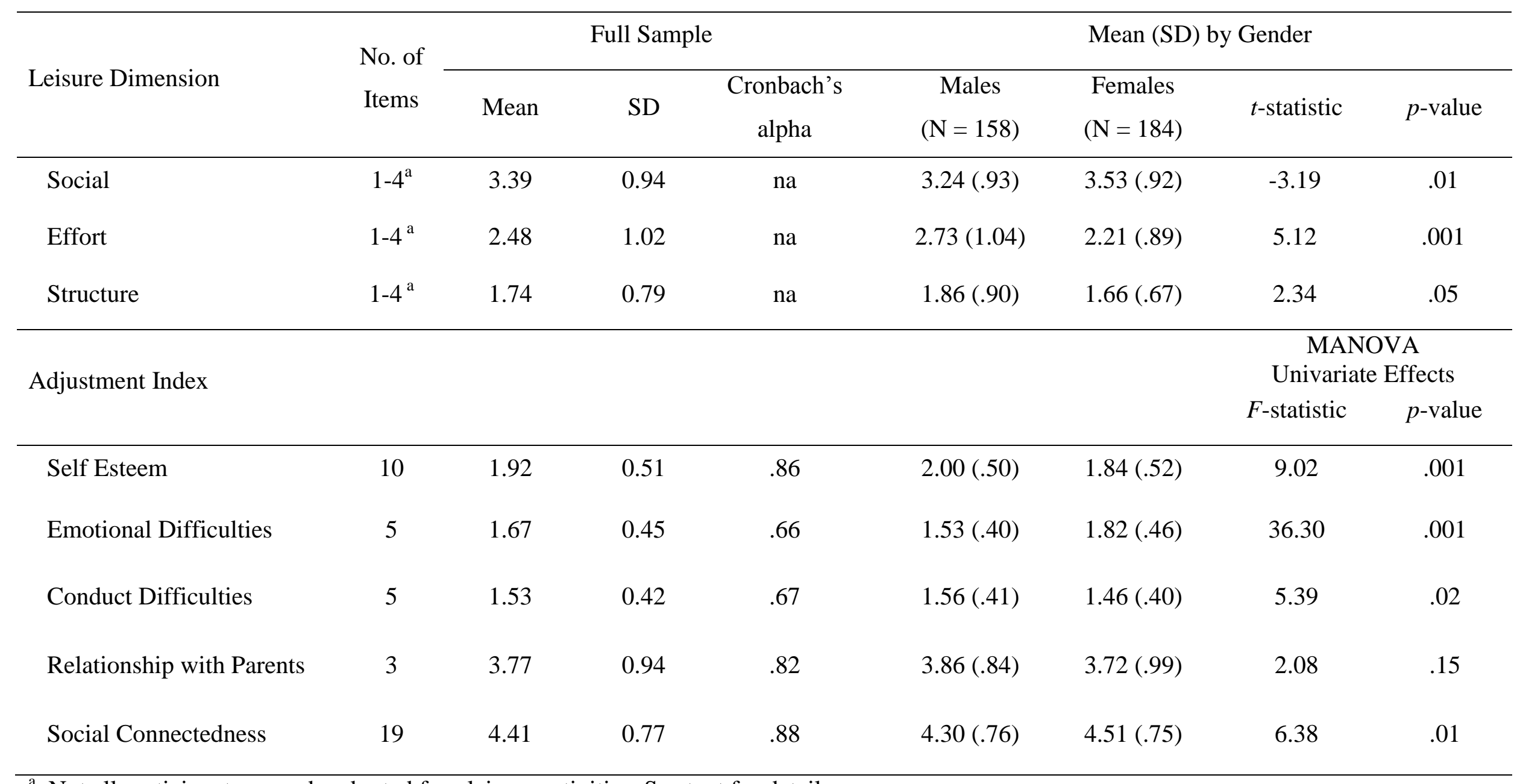

\footnotetext{
${ }^{\mathrm{a}}$ Not all participants named and rated four leisure activities. See text for details.
} 
Table 2

Correlations between Study Variables

\begin{tabular}{|c|c|c|c|c|c|c|c|c|}
\hline & 1 & 2 & 3 & 4 & 5 & 6 & 7 & 8 \\
\hline \multicolumn{9}{|l|}{ 1. Age } \\
\hline 2. Social Leisure & $-.15^{* *}$ & & & & & & & \\
\hline 3. Effortful Leisure & .08 & $.16^{* *}$ & & & & & & \\
\hline 4. Structured Leisure & -.00 & $.15^{* *}$ & $.44 * *$ & & & & & \\
\hline 5. Self Esteem & -.03 & $.15^{* *}$ & $.18^{* *}$ & $.16^{* *}$ & & & & \\
\hline 6. Emotional Difficulties & -.07 & $-.14 * *$ & $-.14 * *$ & -.06 & $-.42 * *$ & & & \\
\hline 7. Conduct Difficulties & -.06 & -.01 & .05 & -.08 & $-.29 * *$ & $.18^{* *}$ & & \\
\hline 8. Relationship / Parents & -.04 & $.12 *$ & .05 & $.11^{*}$ & $.39 * *$ & $-.15^{* *}$ & $-.37 * *$ & \\
\hline 9. Social Connectedness & -.06 & $.38 * *$ & $.11^{*}$ & .08 & $.50 * *$ & $-.27 * *$ & $-.18 * *$ & $.24 * *$ \\
\hline
\end{tabular}


Table 3.

Hierarchical Regression Analyses of Psychosocial Adjustment Indices on Gender, Leisure Dimensions, and Gender x Leisure Interactions.

\begin{tabular}{|c|c|c|c|c|c|c|c|c|c|c|c|c|c|c|c|}
\hline \multirow{4}{*}{$\begin{array}{l}\text { Step } \\
\text { and } \\
\text { Predictor }\end{array}$} & \multicolumn{15}{|c|}{ Psychosocial Adjustment Index ${ }^{a}$} \\
\hline & \multirow{2}{*}{\multicolumn{3}{|c|}{ Self-Esteem }} & \multirow{2}{*}{\multicolumn{3}{|c|}{ Emotional Difficulties }} & \multirow{2}{*}{\multicolumn{3}{|c|}{ Conduct Difficulties }} & \multirow{2}{*}{\multicolumn{3}{|c|}{$\begin{array}{l}\text { Relationship with } \\
\text { Parents }\end{array}$}} & \multirow{2}{*}{\multicolumn{3}{|c|}{ Social Connectedness }} \\
\hline & & & & & & & & & & & & & & & \\
\hline & B & $\mathrm{SE}(\mathrm{B})$ & $\beta$ & $\mathrm{B}$ & $\mathrm{SE}(\mathrm{B})$ & $\beta$ & B & $\mathrm{SE}(\mathrm{B})$ & $\beta$ & B & $\mathrm{SE}(\mathrm{B})$ & $\beta$ & B & $\mathrm{SE}(\mathrm{B})$ & $\beta$ \\
\hline 1. Gender ${ }^{b}$ & .18 & .06 & $.17 * *$ & -.29 & .05 & $-.31 * * *$ & .11 & .05 & $.14 *$ & .12 & .11 & .07 & -.17 & .08 & $-.11 *$ \\
\hline Age & -.02 & .02 & -.04 & -.03 & .02 & -.09 & -.02 & .02 & -.05 & -.04 & .04 & -.05 & -.01 & .03 & -.01 \\
\hline $\mathrm{R}^{2}$ change & \multicolumn{3}{|c|}{$.030 * *$} & \multicolumn{3}{|c|}{$.084 * * *$} & \multicolumn{3}{|c|}{$.020 *$} & \multicolumn{3}{|c|}{.006} & \multicolumn{3}{|c|}{$.030 * *$} \\
\hline 2. Social Leisure & .11 & .04 & $.19^{*}$ & -.13 & .04 & $-.26 * * *$ & -.04 & .03 & -.08 & .25 & .08 & $.25 * *$ & .38 & .06 & $.45^{* * *}$ \\
\hline Effortful Leisure & .09 & .05 & $.17^{*}$ & -.02 & .04 & -.04 & .04 & .04 & .09 & -.05 & .09 & -.06 & .11 & .07 & .14 \\
\hline Structured Leisure & .04 & .06 & .06 & -.01 & .05 & -.01 & -.05 & .05 & -.09 & .11 & .11 & .09 & -.05 & .09 & -.05 \\
\hline $\mathrm{R}^{2}$ change & \multicolumn{3}{|c|}{$.055^{* * *} *$} & \multicolumn{3}{|c|}{$.044 * * *$} & \multicolumn{3}{|c|}{.011} & \multicolumn{3}{|c|}{$.027 *$} & \multicolumn{3}{|c|}{$.134 * * *$} \\
\hline 3. Gender x Social & -.03 & .06 & -.03 & .06 & .06 & .08 & .10 & .05 & $.16^{*}$ & -.24 & .12 & $-.16^{*}$ & -.19 & .09 & $-.15^{*}$ \\
\hline Gender x Effortful & -.11 & .06 & -.15 & -.02 & .06 & -.03 & -.03 & .05 & -.04 & .07 & .12 & .05 & -.11 & .09 & -.09 \\
\hline Gender x Structured & .07 & .08 & .07 & .02 & .07 & .03 & -.03 & .07 & -.04 & .03 & .16 & .02 & .19 & .12 & .13 \\
\hline $\mathrm{R}^{2}$ change & \multicolumn{3}{|c|}{.009} & \multicolumn{3}{|c|}{.003} & \multicolumn{3}{|c|}{.013} & \multicolumn{3}{|c|}{.013} & \multicolumn{3}{|c|}{.018} \\
\hline $\mathrm{R}^{2}$ (Adjusted $\mathrm{R}^{2}$ ) & \multicolumn{3}{|c|}{$.094(.072)$} & \multicolumn{3}{|c|}{$.131(.110)$} & \multicolumn{3}{|c|}{$.045(.022)$} & \multicolumn{3}{|c|}{$.047(.023)$} & \multicolumn{3}{|c|}{$.182(.162)$} \\
\hline
\end{tabular}

a Regression coefficients after all predictors had entered the equation. ${ }^{\mathrm{b}} 0=$ female $1=$ male

$* p<.05 . \quad * * p<.01 . \quad * * * p<.001$. 


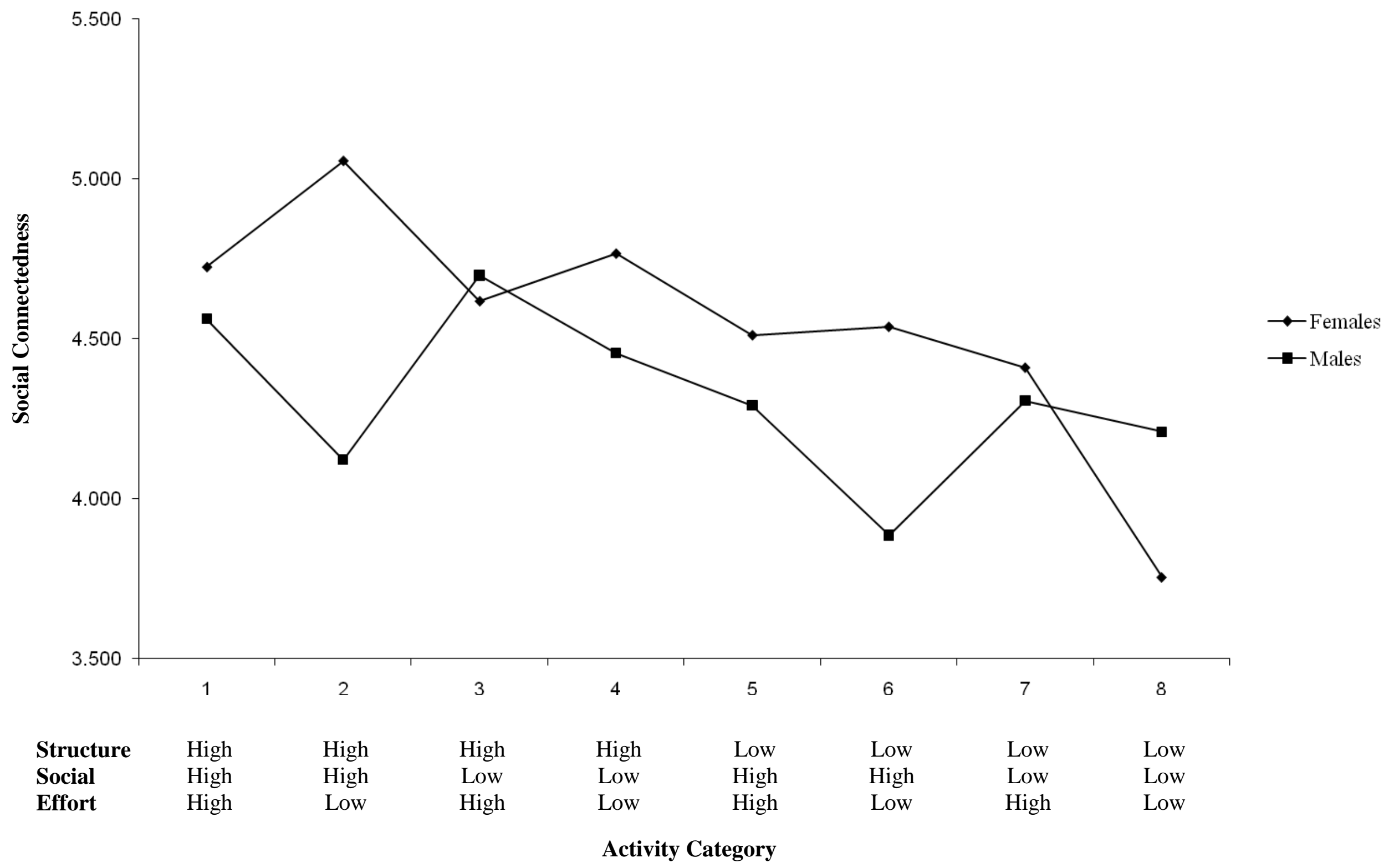


Figure Caption:

Figure 1. Social connectedness for the eight leisure groups by gender. 